\title{
COMPETITION OF CURRENCIES AN ALTERNATIVE TO LEGAL TENDER
}

\section{Kateřina Gawthorpe*}

\begin{abstract}
The aim of this paper is to question the scenario with legal tender law by an analysis of potential competition of alternative currencies. To accomplish such a goal, this study offers an original version of the dynamic macroeconomic model based on the money in the utility function. This model compares the current monetary conditions with the potential situation permitting more currencies circulating alongside. The main assumption about individuals' preferences over stable currencies underlines the whole paper with emphasis on the mathematical model.

The outcome of the model reveals lower inflation rate in scenario with competition among currencies in comparison to the present scenario. This result by itself seems to favour the idea of an exclusion of legal tender clause and allowance of free currency competition. The final simulation of the model, using statistical software, brings to this so far "unambiguous" view scepticism due to possible difficulties during the discovery process.
\end{abstract}

Keywords: alternative currencies, legal tender, money in the utility function, monetary policy JEL Classification: E130

\section{Introduction}

Over four thousands alternative currencies circulated worldwide in about fifty-eight countries in 2002 (see John Turmel list cited in Gomez, 2010, p. 1672). Those, which developed as a substitute to national one, helped individuals to meet transactions in times of monetary crisis. The United States during Great Depression, Germany after WWI, Argentina on the break of the $21^{\text {th }}$ century, New Zealand during the period of neoliberalism or Spain and Greece in the present times, these all represent cases when competing currencies developed as successful alternatives to legal tender. This paper questions the effect of such social movements in case of their free competition to national currency on a monetary side of an economy.

The chief hypothesis of this model is lower inflation rate in the scenario of currency competition. Acceptance of this hypothesis would also support the Hayek's idea about stable purchasing power for currencies in equilibrium without legal tender clause (Issing, 2000). It could also serve as a motivation for countries undergoing economic turmoil accompanied with hyperinflation to support alternative currencies. To analyse the proposition, I construct a variant of money in the utility function model complemented for Matlab simulations.

An influential paper on this topic of currency substitution comes from Sturzenegger (1994), which suggests an eventual reduction of inflation rate for the original currency

* Kateřina Gawthorpe, University of Economics in Prague, Department of Microeconomics, Prague,

Czech Republic (xzimk04@vse.cz);

This work was supported by the University of Economics, Prague, the Faculty of Informatics and Statistics in collaboration with the Faculty of Business Administration under the Grant IGA IG404035. 
after an introduction of a new one. The results of the theoretical model along with a Matlab simulation in this paper also support the conclusion of Sturzenegger (1994) about the reduction of inflation rate on the side of the historically established currency after an introduction of an alternate currency.

The main assumption of the model stands on individuals' preference of stable currency. Friedman (1994) considers inflation as a severe obstacle for current fiat monetary system and attempts to find a solution. It is based on the intuition of papers from Greco (2001), Camera, Craig and Waller (2003), Tullock (1975) and Hayek (1990, p. 76), where stability of currency seems to be of a prior importance for a currency choice, this assumption amplifies when the pivotal money function is to serve as a medium of exchange as Mises (1953) states. The study of Tullock (1975) also understands the dependence of the potential success of a currency on the relative size of inflation for legal tender and the transaction costs of the competing currency. Mizen and Pentecost (1994), Colacelli and Blackburn (2009) and Lascelles (2006) represent other authors understanding the importance of price stability for a success of money in the competition of currencies. Next to the issue of price stability, the study of Colacelli and Blackburn (2009) empirically proves acceptability of a secondary currency in Argentina to increase in periods of national currency shortages. Therefore, there might exist other monetary factors next to inflation, which might trigger currency substitution.

The alternative currency Liberty dollars in the U.S. serves as example of a demand for stable currency. As stated in Hogan (2012) Currency Constant circulating in the 1970s was also demanded for its goal to provide inflationary-proof currency. Similarly, thousands of competing currencies in Germany in the 1920s and alternative currencies Redes de Trueque in Argentina described by Gomez (2010) emerged during high inflationary period with an option to switch to these relatively more stable currencies. The promise of lower inflation represented a sufficient reason for switching to a riskier new secondary currency in times of turmoil. In the presented Model I assume this intuition in an extreme case where the alternative currency bears zero inflation rate. This analysis then reveals the effect of potential free competition of these currencies along with national one on an economy.

An inclusion of money variable into DSGE model starts with Sidrauski (1967). Other papers examining a variant of this model are Walsh (2010), Galí (2008), Woodford (2003) or You (2011). Some subsequent papers use quantitative tools to analyse competition of currencies among countries. For example, Lucas (1982) analyses the effect of two currencies in two-country model, while he assumes lump-sum transfer in dollars or pounds to a trader; the model in this paper stands on an assumption of endogenous money supply (see Yildirimm 2003). Next, Martin (2006) studies cash-in-advance economy to examine currency substitution. Camera, Craig and Waller (2003) construct a model to investigate the competition of two fiat currencies. In opposition to these math-based papers, the DSGE model designed in this study scrutinizes the currency competition within one economy.

Next authors Dowd and Greenaway (1993) emphasize the significance of network effect and switching costs variables for a currency competition research. The model in this study also incorporates these chief variables. The process of switching between currencies itself might not be rapid; all depends on the distribution of threshold levels in the society. The threshold model from Peyton Young (1998) is a benchmark for the understanding of currency substitution in this model or the so called discovery process, which will be examined more thoroughly in the simulation part. 
The paper begins with the formulation of a utility function and budget constraint followed by elementary equations computed from FOCs along with money demand equations and an equation regarding optimal inflation rate. Subsequent simulation in Matlab explores the evolution of demand for one currency relatively to other. Conclusion with the summary of the results is drawn in the end of the study.

\section{The Model}

\subsection{Utility function and budget constraint}

The model in this study follows traditional papers concerning money-in-the-utility function (MIU) models leading to traditional Euler equation such as in Galí (2008, p. 28) or neutrality of money assumption exposed by Lucas (1996).

The representative individual makes a decision over consumption, currency $M_{t}$ and an alternative currency $D_{t}$ in a way to maximize her utility given her budget constraint. The two currency variables enter the utility function in an additive form insinuating a possibility to keep both currencies where each of them yields an individual utility.

$$
U\left(\frac{C_{t}}{P_{t}}, \frac{M_{t}}{P_{t}}, D_{t}\right)=\left\{\frac{1}{1-\sigma}\left(c_{t}\right)^{1-\sigma}+\frac{b}{1-\eta}\left(\frac{M_{t} \delta_{t}^{M \theta}}{P_{t} \pi_{t}^{\gamma}}\right)^{1-\eta}+\frac{\varepsilon}{1-\imath}\left(\frac{D_{t} \delta_{t}^{D \theta}}{S C_{t}}\right)^{1-\imath}\right\}
$$

The separable utility function approximates one illustrated by Galí $(2008$, p. 26) or Benchimol (2015, p. 4). In line with the general utility function, its separable form is assumed to be increasing in all its arguments, continuously differentiable and strictly concave. Parameters $\eta, \sigma, l$ are assumed to be higher than zero and parameters $b$ and $\varepsilon$ reflect respective weights of currency variables $M_{t}$ and $D_{t}$ relatively to the consumption in the utility function. Small letter for $c_{t}$ displays its denomination in real terms. New variables in this representation of the utility function are:

$S C_{t}$ The switching costs variable stands for costs of buying or accepting new currency $D_{t} . D_{t}$ emerged recently, therefore it constitutes only a fraction of overall money stock in the economy. Switching costs consist of transaction costs, time costs from prolonged negotiation with sellers to make them accept the currency, exchange rate costs due to coexistence of multiple circulating currencies and other costs pertaining to discomfort connected with an attempt to use a currency just partially used as a medium of exchange within an economy. The evidence for an existence of these costs exists in the study of North (2014). According to North (2014, p. 256), when businesses carry multiple transactions in a currency every day, the handling, accounting and banking costs of the alternative currency could be so high, that it could outreach its potential benefits.

$\gamma$ This parameter represents a size of an impact of inflation on individual's utility. It belongs into an interval between zero and infinity. The parameter gamma is lower the less an individual minds inflation.

$\pi \quad$ This coefficient represents inflation rate. For the purposes of mathematical calculations it enters the equation in the form one plus the percentage rate of inflation. Altogether $\pi_{t}^{\gamma}$ stands for menu costs (see Mankiw, 1985); the costs of keeping inflating currency. They might symbolize the costs to alter menu prices but also the costs to index prices 
for potential changes in inflation rate in the contracts. Mises (1953) also explicates the peril of inflation. In his opinion, an expansionary monetary policy results in an uneven process of price rises accompanied with unfair distribution of profit stemming from such an action.

In this model, inflation rate is supposed to reduce the real money balances above the decrease of real value of money holdings via price increase. Individuals managing contracts for large payments might suffer from the growth of uncertainty or necessity to make the contract more complex to control for potential escalation in the aggregate price level. A creation of such contract might need a professional expertise of a lawyer raising its costs. The cumbersomeness, inefficiency and distrust represent possible reasons why utility over the real value of a money variable can drop in presence of inflation rate rises.

The variable of inflation rate is free to modification if one finds for example inflation rate volatility or money shortages as more critical factors for currency switching.

$\boldsymbol{C}_{\boldsymbol{t}}=\sum_{k=1}^{N}\left(E_{t}^{k} P_{t}^{k} C_{t}^{k}\right), N=1,2$ is a consumption aggregate composed of goods offered in a currency $k\left(M_{t}\right.$ or/and $\left.D_{t}\right)$ but denominated in $M_{t}$. To obtain the nominal consumption denominated in one currency, the national one, secondary currency $D_{\mathrm{t}}$ is multiplied by the nominal exchange rate.

$\boldsymbol{\beta}_{\boldsymbol{t}}$ Subjective discount factor lying in the interval between zero and one. This factor equals $\frac{1}{1+\theta}$, where theta represents subjective rate of time preference.

$\boldsymbol{b}, \boldsymbol{\varepsilon}$ Respective shares of particular currencies in the utility function.

$\sigma \quad$ Relative risk aversion coefficient.

$\boldsymbol{\delta}$ Network externality parameter. Understanding "medium of exchange" as a dominant (e.g. Mises, 1953) or at least significant function of money couples with an acceptance of significance of network externality and its influence on demand for money. The ability of a currency to serve as a medium of exchange relates to general willingness of others to accept it in payment for debt. The more individuals accept this currency, the higher utility its possession brings to an individual, which originates from its medium of exchange function.

$\boldsymbol{\theta}$ The sensitiveness of one's utility function to network externality connected with a currency. Zero value of theta parameter leads to an exclusion of the impact of network externality parameter on the utility function. Indexes " $M$ " and " $D$ " positioned next to the theta parameter indicate to which currency the particular network externality corresponds.

The agent in this model illustrates an individual managing a bank. Such a modification requires an incorporation of a banker's profit into the constraint replacing product variable. The individual is assumed to manage a bank issuing currency $M_{t}$ where such an issuance raises his profit. Following Mises (1953) idea, the bankers benefit from the inflation the most, as they are the first receivers of lastly printed currency while most of the prices on the market remain yet low. 
The aggregate budget constraint for the whole economy takes the following form:

$$
\frac{C_{t}}{P_{t}}+\frac{B_{t}}{P_{t}}+D_{t}+\frac{M_{t}}{P_{t}}=\left(1+r_{t-1}\right)\left(1+\pi_{t-1}\right) \frac{B_{t-1}}{P_{t-1}}+D_{t-1}+\frac{M_{t-1}}{P_{t}}+F\left(\pi_{t}\right)
$$

The description of the variables in the budget constraint of the representative agent is following:

$C_{t} \quad$ stands for an aggregate consumption variable.

$$
\begin{aligned}
& \left(1+r_{t-1}\right)\left(1+\pi_{t-1}\right) B_{t}=\sum_{k=1}^{N}\left[\left(1+r_{t-1}\right)\left(1+\pi_{t-1}^{k}\right) E_{t}^{k} P_{t}^{k} B_{t}^{k}\right], \\
& N=1,2 .
\end{aligned}
$$

It illustrates an aggregate of bonds traded in a currency " $k$ " (namely $D_{t}$ or/and $M_{t}$ ) but denominated in currency $M_{t}$. Nominal exchange rate enables to convert the denomination of all bonds into the national currency. Where $\left(1+r_{t-1}\right)\left(1+\pi_{t-1}^{k}\right)$ stands for yields of bonds traded in a currency " $k$ ". Since secondary currency $D_{t}$ is assumed to be non-inflationary, its nominal interest rate equals real interest rate.

$\boldsymbol{M}_{\boldsymbol{t}}$ represents a historically developed currency, which has served its purpose for last decades (e.g. dollar). The representative agent as a bank issues this type of currency.

$\boldsymbol{P}_{t} \quad$ is an aggregate of price level, which is denominated in the currency $M_{t}$.

$\boldsymbol{D}_{t}$ depicts an alternative currency to $M_{t}$; it is a new currency not yet fully circulating in the market. This currency is non-inflationary. Since prices do not change over time, the aggregate of prices denominated in $D_{t}$ can be assumed to take on the value of one, as consequence, the real money stock for this currency equals $D_{t}$.

$\boldsymbol{r}_{\boldsymbol{t}}$ represents real interest rate.

$\boldsymbol{i}_{\boldsymbol{t}} \quad$ is nominal interest rate.

$\boldsymbol{F}\left(\boldsymbol{\pi}_{\boldsymbol{t}}\right)$ represents profit of a bank in real terms as a function of inflation.

Inflation is assumed to increase the profit of a banker. Issuing institutions printing thousands of emergency money circulating in Germany in 1923 were not fully free of inflationary tendencies. (Hayek, 1976). Rather the issuers seemed to have been still tempted to inflate the currency into the limit to keep it more stable than the contemporaneous legal tender. Based on this example, I assume profit of the banker to grow with inflation linearly until some point " $x$ ", intuitively until the point where an additional increase in inflation triggers network effect. It could be a point where a marginal individual becomes indifferent between currencies $D_{t}$ and $M_{t}$ given its threshold level.

This setting leads to the following conditions, which illustrate an outcome to an optimization problem defined by the separable utility function (see Equation 1) with respect to the budget constraint (see Equation 2).

The Bellman equation (see Rosu, 2002) satisfying the transversality condition for state variables, real money variable for both currencies and bonds, results in the FOCs.

Integrating the first-order conditions (FOCs), one obtains the following Euler equation:

$$
c_{t}^{-\sigma}=E_{t} \beta\left[\left(1+r_{t}\right) c_{t+1}^{-\sigma}\right]
$$

As one can notice, the traditional Euler equation does not alter with respect to the number of various currencies in circulation. According to this equation, it does not pay off to 
decrease consumption today and invest the remaining money into the bonds in order to foster the consumption in time $t+1$ as the marginal utility of current consumption $c_{t}^{-\sigma}$ equals the expected discounted marginal utility of consumption in time $t$ plus one: $c_{t}^{-\sigma}$ increased by the interest rate as a revenue for investing into bonds.

Combining the FOCs in a traditional way to obtain money demand, the following equation appears:

$$
M_{t}=\left(\frac{1+i_{t}}{i_{t}} \frac{b}{c_{t}^{-\sigma}}\right)^{\frac{1}{\eta}}\left(\frac{\delta_{t}^{M \theta}}{\pi_{t}^{\gamma} P_{t}}\right)^{\frac{1-\eta}{\eta}}
$$

It is possible to detect a standard money demand (see Walsh, 2010 or Obstfeld and Rogoff, 1996) extended for new variables. The money demand also corresponds with the findings of Friedman (1971), who suggests a clear relationship between money demand, output, nominal interest rate but also price change, which is in this study modelled as inflation rate. To obtain the nominal interest rate expression, the Fisher equation from Irving Fisher (1896) has been applied.

$$
D_{t}=\left(\frac{1+r_{t}}{r_{t}} \frac{\varepsilon}{c_{t}^{-\sigma}}\right)^{\frac{1}{t}}\left(\frac{\delta_{t}^{D \theta}}{S C_{t}}\right)^{\frac{1-t}{l}}
$$

This equation is also a combination of the FOCs using traditional mathematical operations. It shows a similar relationship such as the Equation 4 but for the currency $D_{t}$.

The respective marginal rate of substitution between the historically prevailing currency and the alternative currency:

$$
M R S_{M_{t} D_{t}}: \frac{b\left(\frac{M_{t}}{P_{t}} \frac{\delta_{t}^{M \theta}}{\pi_{t}^{\gamma}}\right)^{1-\eta}}{\varepsilon\left(\frac{D_{t}}{S C_{t}} \delta_{t}^{D \theta}\right)^{1-l}} \frac{D_{t}}{M_{t}}=\frac{\frac{\lambda_{t}}{P_{t}}-\beta E_{t} \frac{\lambda_{t+1}}{P_{t+1}}}{\lambda_{t}-\beta \lambda_{t+1}}
$$

Transformation of the marginal rate of substitution between the two currencies along with the simplification $l=\eta$ brings the subsequent product:

$$
\frac{m_{t}}{d_{t}}=\left(\frac{b}{\varepsilon} \frac{S C_{t}^{1-\eta} \frac{r_{t}}{1+r_{t}} \delta_{t}^{M \theta(1-\eta)}}{\pi_{t}^{\gamma(1-\eta)} \frac{i_{t}}{1+i_{t}} \delta_{t}^{D \theta(1-\eta)} P_{t}}\right)^{\frac{1}{\eta}}
$$

The attractiveness of this equation originates in its clarity about the influence of the variables as well as parameters on the ratio between the demands for individual currencies in real terms. In the scenario where the currencies $M_{\mathrm{t}}$ and $D_{t}$ stand in a fair competition without legal tender law, the demands for particular currencies appear interconnected. The relationship between individual variables seems intuitive. Raise in the variable switching costs reduces demand for alternative currency while inflation rate as well as nominal interest rate has a negative effect on the demand for the currency $M_{t}$; network externality variable is positively correlated with particular money demands. 


\subsection{Optimal inflation rate}

The subsequent part consists of the derivation of simple Lagrangian in order to investigate the optimal size of parameter "inflation rate" for scenario with and without legal tender clause.

The Equation 7 confirms the positive correlation between currency variable $D_{t}$ and inflation rate. This relationship between the growth of demand for this currency and subsequent increase in its circulation with an increment in the inflation rate could then be rewritten as Equation 8. The alternative currency Constant circulating in the 1970s, the demand for more stable local currencies during hyperinflation in Germany in the 1920s or emergence of the alternative currencies Redes de Trueque in Argentina (see Gomez, 2010) during severe inflationary period prove demand for and willingness to switch to a new potentially riskier currencies in times of turmoil. On the other hand, currency Liberty dollars displays a similar demand for stable currency in times of relatively economically stable period. (Hogan, 2012)

The intuition behind this simplified expression is the consequence of higher inflation rate on individuals' demand for the currency and finally individuals' utility from switching the previous legal tender for this non-inflationary currency.

$$
D_{t}=b \pi_{t}^{s}
$$

Parameter " $b$ " captures all the other variables affecting the size of demand for the new currency and " $s$ " the parameters, which exponentially influence its proportion.

An application of the Envelope theorem on the original maximization problem with the use of Lagrangian results in:

$$
\pi_{t}^{C^{*}}=\frac{\gamma b\left(\frac{M_{t}}{P_{t}} \frac{\delta_{t}^{M \theta}}{\pi_{t}^{\gamma}}\right)^{1-\eta}-\varepsilon s\left(\frac{D_{t} \delta_{t}^{D \theta}}{S C_{t}}\right)^{1-t}}{\lambda_{t} F_{\pi}}=\frac{\gamma M U_{M_{t}} M_{t}-M U_{D_{t}} s D_{t}}{\lambda_{t} F_{\pi}}
$$

The index " $c$ " next to the optimal value for the inflation rate variable stands for the scenario of competition between currencies.

The variant where only one monopolistic currency circulates due to legal tender clause hardening the fair competition among all currencies looks following:

$$
\pi_{t}^{*}=\frac{\gamma M U_{M_{t}} M_{t}}{\lambda_{t} F_{\pi_{t}}}
$$

Comparison of the Equations 9 and 10 exhibits lower inflation rate for the case with the presence of competition among currencies. In particular, the higher the marginal utility of currency $D_{t}$ or the amount of the currency $D_{t}$ in circulation, the lower the incentives are on the side of the banker issuing the currency $M_{t}$ to inflate as it attempts to retain its competitiveness.

In conclusion, the issuing institutions in presence of competition are motivated to keep inflation rate lower in relation to inflation rate and switching costs of other currencies. The reason for lower inflation rate originates in the incentives of issuing institutions to maintain or intensify money demand. If authors Colacelli and Blackburn (2009), Lascelles 
(2006), Tullock (1975) and others describe inflation rate as a crucial determinant in switching between currencies, then inflation rate should be lower in an economy with currency competition such as the Equation 10 in comparison to 9 illustrates. Sturzenegger (1994) supports an equivalent intuition about positive effect of currency competition on inflation rate of the legal tender.

\section{Simulation in MATLAB}

The aim of this section is to simulate an evolution of the inflation rate modelled by the Equation 9. The simulation has been constructed in the programme Matlab, the code along with the parameter estimates are in the Appendix. Understanding the operation of the proposed model can help to examine its relevance to capture real-life scenarios as well as it answers the question of the discovery process.

The calibration of this model originates in the studies of (Benchimol, 2015; Foresti \& Napolitano, 2014 and Valev, 2010).

\section{Figure 1 The Amount of $M_{t}$ Prevails the One of $D_{t}$}

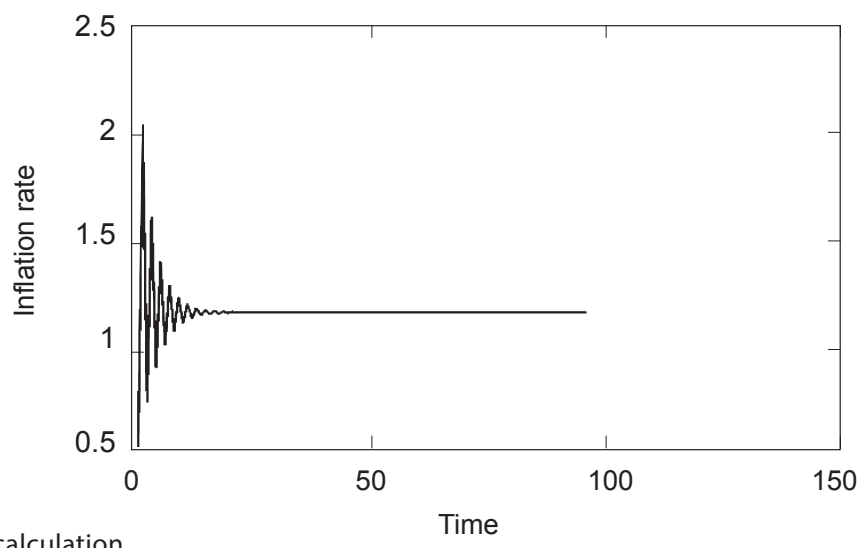

Source: Authors calculation.

Figure 1 displays the evolution of inflation rate over time. It is a Matlab simulation of the Equation 9 where all values equal to one except for parameter eta and lota, which are set to 0.5 and the value of the currency variable $M_{t}$ to 30 . The initial value for inflation rate is set up to equal to 3 . In such a scenario the variable inflation rate oscillates around the value 1.186. The oscillatory evolution of the inflation rate over time becomes intuitive, ones examining the Equation 9. The positive value of initial inflation rate decreases individual's utility from holding on the previous legal tender in turn reducing the optimal level of inflation rate for the second period as banker wants to allure clients to keep her currency. Lower inflation rate in the second period raises individual's utility from holding such a currency and results in an elevation of the optimal level of inflation rate for the third period. The rise of inflation rate follows banker's incentives to take subsequent benefit over higher demand for her currency by increasing inflation rate. However, since eta is not zero, but 0.5 , the oscillation converges to a stable linear trend around the value of 1.186. Such a relatively high value of inflation rate is due to sizable original value of the currency $M_{t}$. 
Comparing this result to Figure 5 the interpretation could be as an increase in the optimal value of inflation rate with the rise of the amount of the currency $M_{t}$ circulating. By other words, weak currency competition results in an elevation of the inflation rate for the widespread currency.

\section{Figure 2 | Rise of the Amount of the Currency $D_{t}$}

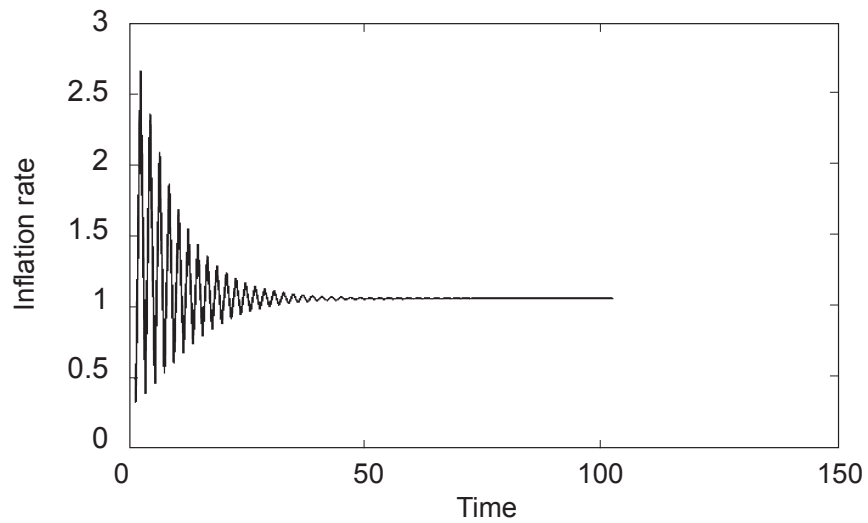

Source: Authors calculation.

The Figure 2 appears similar to Figure 1 except for the size of circulating amount for the alternative currency equals to 3 . In comparison to Figure 1, the rise in the monetary stock of $D_{t}$ results in a perceivable increase in oscillation of inflation rate for the currency $M_{t}$ lasting for a longer period of time and oscillating around the value 1.089. The inflation rate of $M_{t}$ is therefore destabilized by willingness of individuals to switch to a competing currency. In detail, calculating the level of oscillation one obtains 1.502 for the Figure 1 by summing the absolute value of its first differences, for the Figure 2 the level equals to 2.344. According to such a result, the price level stability would be severely disrupted with an increase of the currency $D_{t}$.

Summing the results from the Figure 1 and 2, the discovery process could include a long period of destabilization of price level during the switching although potentially concluding in higher price level stability in comparison to the scenario without the competition of currencies (compare Equations 9 and 10).

It would be a question, whether the size of the benefits from the resulting price level stability and overall lower inflation rate would exceed the costs of critical switching period. In any case, the role of institutions would become significant as they could decrease the length of switching process and its austerity. Also, over long periods of time the acceptance and switching between currencies could be more flexible as individuals could hesitate less to abandon a currency loosing its value.

On the Figure 3, one can see an increase in the trend towards which inflation rate converges after the rise of network externality for the currency $M_{t}$ after fifty periods from 1 to 3 . Alternatively, on the Figure 4, the network externality for the alternative currency is raised from one to three after fifty periods, inflation rate of the historically developed currency would now converge towards a lower value. 

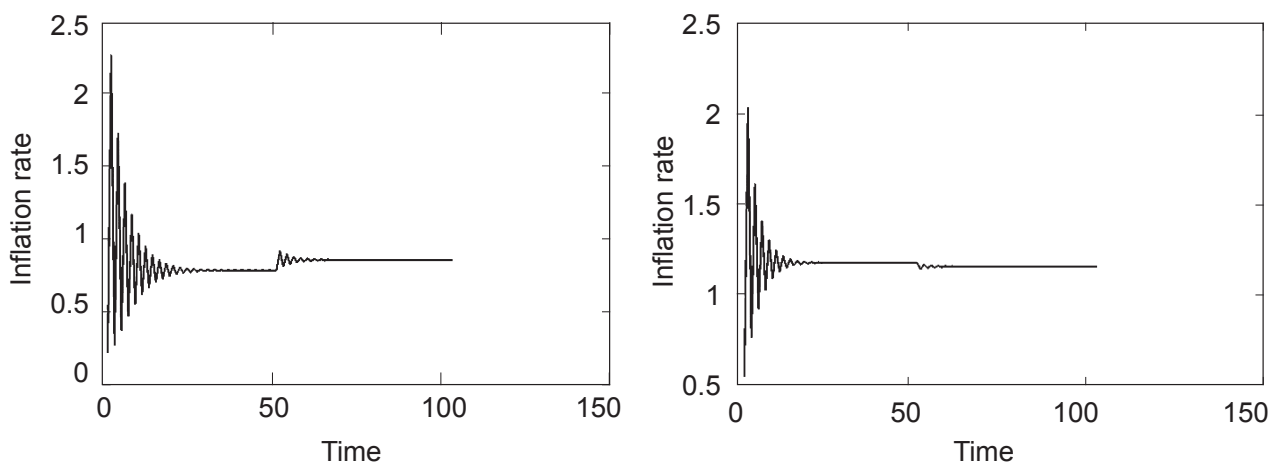

Source: Authors calculation.

Network externality variable for the alternative currency positively affects inflation rate of $M_{t}$. As the issuers of this latter currency have to face in such case a stronger competition, they incline to tighten their monetary policy.

Figure 5 | $M_{t}$ Equals $D_{t}$

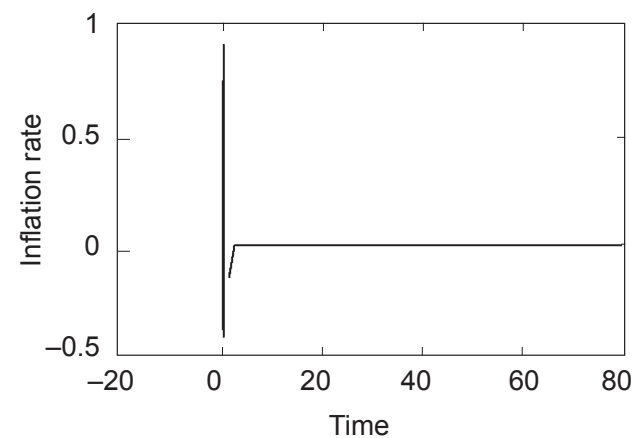

Figure 6 | Only $M_{t}$ Circulates

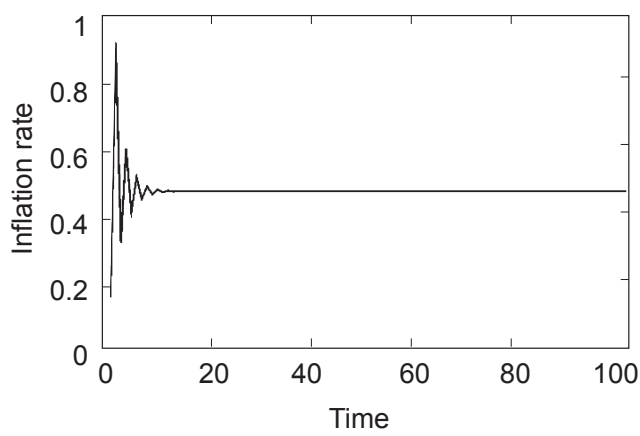

Source: Authors calculation.

Figures 5 and 6 are again simulated using the Equation 9. These two figures illustrate the comparison of the scenario with two currencies and only one currency circulating, respectively. In the Figure 5 I set the value of the currency $M_{t}$ to 1 as well as for the currency $D_{t}$. In the Figure 6, only the currency $M_{t}$ is present. Comparing these figures, the inflation rate tends to fluctuate around the lower value in the case of competition of currencies.

The simulations in Matlab proved my hypothesis with regards to the Equation 9. An optimal inflation rate has a tendency to stabilize around zero in the scenario of free competition of currencies where the amount of currencies circulating equates, ceteris paribus, Figure 5. This result corresponds to the idea of Hayek (1984, p.41) or Hogan (2012), who understand a benign impact of alternative currencies on price stability. Schwartz (1984, p.116) offers an example of free currency competition in Scotland, which he explains as not inflationary. According to him self-regulation of issuance institution due 
to the possibility of clearing house to quote their notes with a discount served better than state regulation. (Schwartz, 1984, p. 118). Lower inflation rate was also connected with alternative currencies in Germany in 1923, which exhibited lower inflation in relation to legal tender. The currency Constant emerging in the 1970s in the United States proved demand for inflation-proof currency. (Swann and Witt, 1995) Liberty dollars was another American alternative currency. It launched in economically stable environment called the Great Moderation in 1998 in the United States. This currency showed to be less inflationary than contemporaneous dollar (Hogan, 2012, p. 30).

The oscillatory evolution of inflation rate over time requires a further research to explore a possible emergence of immense burden in terms of price instability during the switching period such as Figures 1 and 2 insinuate. In accordance to these figures, the instability would be linked to an unsuccessful currency failing in the currency competition. This volatility of prices could affect the overall economic prosperity.

The obstacle of inflation - volatility could harshen the position of alternative currencies on the market. Shenfield (1984) describes the circulation of private notes in Scotland on the merge of the 18th and 19th centuries. During the period some private notes previously non-inflationary were subject to inflation. The subsequent lack of trust in banking system and following panic often caused private banks to go out of business. Only sound currency was demanded and valued by customers as Shenfield (1984) describes. The success of competing currencies could then be severely jeopardized in case of frequent switching between currencies.

The United States in the beginning of the $19^{\text {th }}$ century illustrates as well how widespread demand for a private currency first relatively stable can conclude in its price instability fostered by financial motives of issuers (Vaubel, 1984). Although, the dynamics might in the end result in lower inflation, a lack of competition along with high demand for few currencies seems to motivate issuers to loose its low-inflationary policies. This dynamics from low to high inflation then already appeared in the history.

Free competition of currencies would then bring about a mixed effect. On the one hand, the economy could end up with a currency according to individuals' preferences converging to the lower value of inflation rate. On the other hand, the period of switching would decrease the price stability for relatively long period of time. This outcome questions the overall price stabilizing effect of the introduction of alternative currencies Hogan (2012) describes.

This negative consequence could be mitigated by establishing formal institutions shortening the switching period or deepening the willingness of most individuals to hold on the more stable currency. Risk adverse individual may be at first doubtful about the future of an alternative currency and its stability. If a central institution investigates its stability ahead before establishing the right institutions to support a stable currency and quicken the exit of an unstable one, individuals might be more prone to quickly switch to the more stable currency, considerably reducing the switching period.

\section{Conclusion}

This paper presents a theoretical analysis based on the version of the money-in-the-utility function model scrutinizing an alternative scenario to monopoly position of national currency. The chief hypothesis of the study is higher stability of a currency value in presence of alternative currencies to legal tender. 
It seeks to challenge the viability of the argument of Hayek (1990) in favour of the competition of currencies. The widespread circulation of more than four thousands alternative currencies worldwide incentivizes this study to question the monetary effects of a potential raise of their position as legitimate substitutes to legal tender. Those currencies emerging as currency substitutes help individuals to carry their transactions in the crisisstroke countries.

The model reveals convergence towards lower inflation rate for the scenario with two circulating currencies. However, according to the analytical representation of the model, the fluctuations of the inflation on the way to such state might not be monotonic but rather oscillatory with a longer destabilizing period for the price level of the previous currency being it less demanded. In the beginning, when the competition of currencies raises strong belief and trust of individuals to switch to preferable currency as well as institutional framework easing the exit of unsuccessful currency could smoothen the process. The outcome of the study is based on the main assumption in the model stating individuals' preferences over less inflationary currency.

Subsequent research could analyse the incentives of individuals behind individuals' potential decision among currencies. While authors such as Greco (2001) understand inflation rate as an important factor for currency choice, they may not need to be the only ones. In such case, mathematical model could be extended for additional variables reflecting individuals' incentives to demand alternative currency.

In conclusion, under the assumption of preference of stable low inflationary currency and quick spread of information, the competition of currencies could result in lower inflationary scenario. Issuing banks are compelled to encounter individuals' preferences over currencies by offering more stable currency. Such outcome could be especially of an interest to developing countries, which are more frequently challenged by higher rates of inflation. The scenario without legal tender clause should be advantageous where individuals could pick what is in their best interest and the process should be slow enough to eliminate potential errors, however, strong institutions speeding up the switching process would be of crucial importance.

\section{Appendix}

\section{Parameter estimates}

The utility function in the model of Benchimol (2015) separable in consumption and money variable assimilates the function estimated in this model. Benchimol (2015) estimates parameters using Bayesian techniques extracting data from the euro area. Parameters $b$, epsilon and sigma correspond to ones in his study.

Unfortunately, there is a lack of research concerning the elasticity of substitution between two currencies. I assume parameter 0.5 , a middle way between perfect substitutes and Cobb-Douglas utility over these currencies.

The log-linearized Equation (4) suggests the size of the effect of inflation rate on money demand to equal parameter $\gamma\left(\frac{1-\eta}{\eta}\right)$. Cointegration analysis then provides this coefficient with real data. Study (Coenen \& Vega, 2001, p. 7) suggests the size of the coefficient for long-run demand for the EU to equal to 1.2, the average of five out of seven models estimated 
in the article (Belke \& Czudaj, 2010, p. 39) using Johansen procedure for euro currency equalize 1.2 as well. Since the ratio of etas equalize one in the model, the parameter gama corresponds to the value of 1.2.

Valev (2010) measures the effect of Network externality for euro and dollar on demand for a national currency in Bulgaria. The outcome indicates the demand for Bulgarian Lev to be affected by network externality variable by 0.21 percentage points. The Table 1 displays the parameters of interest.

Table 1 | Structural Parameters

\begin{tabular}{|l|l|c|}
\hline$b$ & $b$ & 0.25 \\
\hline$\varepsilon$ & epsilon & 0.25 \\
\hline$\eta$ & eta & 0.5 \\
\hline$\gamma$ & gama & 1.2 \\
\hline$l$ & iota & 0.5 \\
\hline$\sigma$ & sigma & 2 \\
\hline$D \theta$ & theta $D$ & 0.21 \\
\hline$M \theta$ & theta $M$ & 0.21 \\
\hline
\end{tabular}

\section{The Matlab Code for Simulation}

The values for individual variables as well as parameters were already described in the paper and changed according to the research question.

for $i=1: 100$

Mum $=(($ Mt.*(delta(i)).^theta)./(Pt(i).*(inf.^Gama))).^(1-eta);

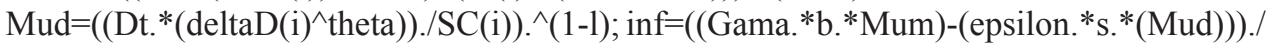
(Lambda(i). *F(i)); sum_vec(i)=inf;

$\% \operatorname{disp}($ sum_vec)

plot(sum_vec,'k-','LineWidth',1.5)

xlabel('TIME')

ylabel('INFLATION RATE')

title('Evolution of Inflation Rate Over Time','Fontsize',14)

end

\section{References}

Belke, A. H., Czudaj, R. (2010). Is Euro Area Money Demand (still) Stable? Cointegrated VAR versus Single Equation Techniques. Ruhr Economic Paper No. 171.

Benchimol, J. (2015). Money in the Production Function: A New Keynesian DSGE Perspective. Southern Economic Journal, 82(1), 152-184, http://dx.doi.org/10.4284/0038-4038-2011.197 
Camera, G., Craig, B., Waller, C. J. (2004). Currency Competition in a Fundamental Model of Money. Journal of International Economics, 64(2), 521-544, http://dx.doi.org/10.1016/j. jinteco.2003.09.002

Coenen, G., Vega, J. L. (2001). The Demand for M3 in the Euro Area. Journal of Applied Econometrics, 16(6), 727-748, http://dx.doi.org/10.1002/jae.629

Colacelli, M., Blackburn, D. (2009). Secondary Currency: An Empirical Analysis. Journal of Monetary Economics, 56(3), 295-308, http://dx.doi.org/10.1016/j.jmoneco.2009.02.002

Dowd, K., Greenaway, D. (1993). Currency Competition, Network Externalities and Switching Costs: Towards an Alternative View of Optimal Currency Areas. Economic Journal, 103(420), 1180-1189, http://dx.doi.org/10.2307/2234244

Fisher, I. (1896). Appreciation and Interest. American Economic Association, 11(4), 331-442. Available at: http://www.policonomics.com/wp-content/uploads/Appreciation-and-Interest.pdf

Friedman, M. (1970). A Theoretical Framework for Monetary Analysis. Journal of Political Economy, 78(2), 193-238, http://dx.doi.org/10.1086/259623

Friedman, M. (1994). Money Mischief: Episodes in Monetary History. San Diego: Harcourt Brace and Co. ISBN: 978-0156619301.

Galí, J. (2008). Monetary Policy, Inflation, and the Business Cycle: an Introduction to the New Keynesian Framework. Princeton, N.J: Princeton University Press. ISBN: 978-0691133164.

Gomez, G. M. (2010). What Was the Deal for the Participants of the Argentine Local Currency Systems, the Redes de Trueque? Environment and Planning, 42(7), 1669-1685, http://dx.doi.org/10.1068/a42309

Granovetter, M. (1978). Threshold Models of Collective Behavior. American Journal of Sociology, 83(6), 1420-1443, http://dx.doi.org/10.1086/226707

Greco, T. H. (2001). Money: Understanding and Creating Alternatives to Legal Tender. White River Junction, Vt: Chelsea Green Pub. ISBN: 9781890132378

Hayek, F. A. (1976). Denationalisation of Money: The Argument Refined. Ludwig von Mises Institute. ISBN: 9781610161411.

Hayek, F. A. (1984). Central Bank Monopoly in the History of Economic Thought: A Century of Myopia in England. Currency Competition and Monetary Union. ISBN 978-90-247-2817-6.

Hayek, F. A. (1990). Denationalisation of Money. Coronet Books Inc. ISBN: 978-0255362399.

Hogan, T. L. (2012). Competition in Currency: The Potential for Private Money. Rochester, NY: Social Science Research Network. Retrieved from http://papers.ssrn.com/abstract=2224118

Issing, O. (2000). Hayek, Currency Competition and European Monetary Union: Eight Annual IEA Hayek Memorial Lecture. Given in London on Thursday, 27 May 1999. London: Institute of Economic Affairs. Available at: https://www.ecb.europa.eu/press/key/date/1999/html/ sp990527.en.html

Lascelles, C. (2006). Complementary Currencies: Mutual Credit Currency Systems and the Challenge of Globalization. Duke University. Available at: https://econ.duke.edu/ uploads/assets/dje/2006/Lascelles.pdf

Lucas, R. E. (1982). Interest Rates and Currency Prices in a Two-Country World. Journal of Monetary Economics, 10(3), 335-359, http://dx.doi.org/10.1016/0304-3932(82)90032-0

Lucas, R. E., Jr. (1996). Nobel Lecture: Monetary Neutrality. Journal of Political Economy, 104(4), 661-682, http://dx.doi.org/10.1086/262037

Mankiw, G. N. (1985). Small Menu Costs and Large Business Cycles: A Macroeconomic Model of Monopoly. The Quarterly Journal of Economics, 100(2), 529-539,

http://dx.doi.org/10.2307/1885395 
Mises, L. von (1953). The Theory of Money and Credit. United States: Tribeca Books. ISBN: 9781612931098.

Obstfeld, M., Rogoff, K. (1996). Foundations of International Macroeconomics. Cambridge, Mass: MIT Press. ISBN: 9780262150477.

Martin, A. (2006). Endogenous Multiple Currencies. Journal of Money, Credit and Banking, 38(1), 245-262, http://dx.doi.org/10.1353/mcb.2006.0019

Mizen P., Pentecost E. J. (1994). Evaluating the Empirical Evidence for Currency Substitution: A Case Study of the Demand for Sterling in Europe. The Economic Journal, 104(426), 1057-1069, http://dx.doi.org/10.2307/2235064

North, P. (2014). Ten Square Miles Surrounded by Reality? Materialising Alternative Economies Using Local Currencies. Antipode, 46(1), 246-265, http://dx.doi.org/10.1111/anti.12039

Rosu, I. (2002). The Bellman Principle of Optimality. Available at: http://webhost.hec.fr/rosu/ research/notes/bellman.pdf

Schwartz, P. (1984). Central Bank Monopoly in the History of Economic Thought: A Century of Myopia in England. Currency Competition and Monetary Union, 8, ISBN: 978-90-247-28176, 95-126.

Shenfield (1984). Central Bank Monopoly in the History of Economic Thought: A Century of Myopia in England. Currency Competition and Monetary Union, 8, ISBN 978-90-247-2817-6, 74-75.

Sidrauski, M. (1967). Rational Choice and Patterns of Growth in a Monetary Economy. The American Economic Review, 57(2), 534-544. Available at: http://faculty.econ.ucdavis.edu/ faculty/kdsalyer/LECTURES/Ecn200e/sidrauski_money.pdf

Sturzenegger, F. A. (1994). Hyperinflation with Currency Substitution: Introducing an Indexed currency. Journal of Money, Credit and Banking, 26(3), 377-395, http://dx.doi.org/10.2307/2078008

Swann, R., Witt, S. (1995). Local Currencies: Catalysts for Sustainable Regional Economies. Available at: http://library.uniteddiversity.coop/Community_Currencies/local_currencies_catalysts.pdf

Tullock, G. (1975). Competing Monies. Journal of Money, Credit and Banking, 7(4), 491-497, http://dx.doi.org/10.2307/1991757

Valev, N. T. (2010). The Hysteresis of Currency Substitution: Currency Risk vs. Network Externalities. Journal of International Money and Finance, 29(2), 224-235, http://dx.doi.org/10.1016/j.jimonfin.2009.06.017

Vaubel (1984). Central Bank Monopoly in the History of Economic Thought: A Century of Myopia in England. Currency Competition and Monetary Union, 8, ISBN: 978-90-247-2817-6, 59-74.

Walsh, C. E. (2010). Monetary Theory and Policy (3rd Ed.). Cambridge, Mass: MIT Press. ISBN: 9780262013772.

Woodford, M. (2003). Interest and Prices: Foundations of a Theory of Monetary Policy. Princeton, N.J. ; Woodstock, Oxfordshire, England: Princeton University Press. ISBN: 9780691010496.

Yildirim, J. (2003). Currency Substitution and the Demand for Money in Five European Union Countries. Journal of Applied Economics, 6(2), 361-383. Available at: http://www.ucema.edu. ar/publicaciones/download/volume6/yildirim.pdf

Young, H. P. (1998). Individual Strategy and Social Structure: an Evolutionary Theory of Institutions. Princeton, N.J.: Princeton University Press. 